\title{
Genetic Predisposition for Dermal Problems in Hexavalent Chromium Exposed Population
}

\author{
Priti Sharma, ${ }^{1}$ Vipin Bihari, ${ }^{2}$ Sudhir K. Agarwal, ${ }^{3}$ and Sudhir K. Goel ${ }^{1}$ \\ ${ }^{1}$ Petroleum Toxicology Division, CSIR-Indian Institute of Toxicology Research (CSIR-IITR), Lucknow 226001, India \\ ${ }^{2}$ Epidemiology Division, CSIR-IITR, Lucknow 226001, India \\ ${ }^{3}$ Department of Biochemistry, Lucknow University, Lucknow 226007, India
}

Correspondence should be addressed to Sudhir K. Goel, sudhir.ji@gmail.com

Received 3 April 2012; Revised 17 May 2012; Accepted 17 May 2012

Academic Editor: Sherif F. El-Khamisy

Copyright (C) 2012 Priti Sharma et al. This is an open access article distributed under the Creative Commons Attribution License, which permits unrestricted use, distribution, and reproduction in any medium, provided the original work is properly cited.

\begin{abstract}
We studied the effect of genetic susceptibility on hexavalent chromium induced dermal adversities. The health status of population was examined from the areas of Kanpur (India) having the elevated hexavalent chromium levels in groundwater. Blood samples were collected for DNA isolation to conduct polymorphic determination of genes, namely: NQO1 (C609T), hOGG1 (C1245G), GSTT1, and GSTM1 (deletion). Symptomatic exposed subjects $(n=38)$ were compared with asymptomatic exposed subjects $(n=108)$ along with asymptomatic controls $(n=148)$ from a non contaminated reference community. Exposed symptomatic group consisted of $36.8 \%$ subjects who were GSTM1 null genotyped as compared to asymptomatic where only $19.4 \%$ subjects were null. The exposed subjects with GSTM1 null genotype were more susceptible to dermal adversities in comparison with wild genotyped subjects $(\mathrm{OR}=2.42 ; 95 \% \mathrm{CI}=1.071-5.451)$. Age, smoking, gender or duration of residence were not found to have any confounding effect towards this association. Association with other genes was not statistically significant, nonetheless, possible contribution by these genes cannot be ruled out. In conclusion, variation in the polymorphic status of GSTM1 gene may influence dermal outcomes among residents from $\mathrm{Cr}(\mathrm{VI})$ contaminated areas. Further studies are therefore, needed to examine these observations among different population groups.
\end{abstract}

\section{Introduction}

Chromium in trivalent form is a trace metal that humans require as an important bioelement for its exceptional role in metabolic processes [1]. On the other hand, the hexavalent form of $\mathrm{Cr}[\mathrm{Cr}(\mathrm{VI})]$ is a toxic form and is reported to have deleterious health effects on the human beings. $\mathrm{Cr}$ (VI) has widespread applications in industries involved in leather tanning, manufacturing chrome sulfate, paints, dyes, and so forth. Occupational exposure to $\mathrm{Cr}(\mathrm{VI})$ is reported to cause contact dermatitis among workers [2]. Due to the improper ways of waste disposal from these industries, exposure to $\mathrm{Cr}(\mathrm{VI})$ is not limited at occupational environment but expands to areas in the vicinity of human residence [3-5].

Whereas there are extensive data available on the dermatological adversities due to occupational exposure of chromium compounds, only limited information is available concerning the risk and its mechanism involved following environmental exposure. Findings of the epidemiological studies on dermal outcomes among general populations have been equivocal. In a longitudinal health effects survey conducted by the Tokyo Metropolitan Government Bureau of Sanitation [6], an increase in incidence of contact dermatitis and eczema of the hands from residents in the contaminated areas compared to the controls was reported. In the contrary, self- reported-assessment-based study conducted among residents from a contaminated site at Glasglow found no evidence of harm to the health of residents [7]. The experimental studies also dictate remarkable variations in the behavior of chromium amongst individuals. Previous studies have reported large differences in the reduction of $\mathrm{Cr}(\mathrm{VI})$ to its lower oxidation states in human plasma and blood cells of different individuals [8-10] and chromium uptake in lymphoblastic cell lines derived from three different individuals [11]. In another study on chromium-sensitive subjects, dichromate evoked a positive patch test rate in 
only $8 \%$ of the subjects at $0.001 \%$ and $4 \%$ at $0.01 \%$ [12]. These observations point towards interindividual variability in response towards $\mathrm{Cr}(\mathrm{VI})$ exposure among the human beings.

Twin studies show that the genetic differences account for about a quarter of the variance in adult human lifespan. Genetic differences also contribute towards selection of genetically inherited tolerance among populations exposed to environmental toxicant [13]. With expanding involvement of genetic biodiversity in deciding biological response to various agents, it seems practical to consider the role of genetic factors towards health outcomes among general population exposed to $\mathrm{Cr}(\mathrm{VI})$.

These genetic factors may correspond to those enzymes involved in the processes of $\mathrm{Cr}(\mathrm{VI})$ reduction inside the cell and the subsequent consequences [14]. So, by affecting the biological fate of $\mathrm{Cr}(\mathrm{VI})$ and its impact on various cell compartments, these genetic factors may influence the toxic impacts of $\mathrm{Cr}(\mathrm{VI})$. One out of these is $\mathrm{NAD}(\mathrm{P}) \mathrm{H}$ :quinone oxidoreductase (NQO1), also known as DT-diaphorase, reported to be involved in $\mathrm{Cr}(\mathrm{VI})$ reduction [15]. Existence of polymorphic forms of NQO1 gene among human population is well documented. A transition of base $\mathrm{C}$ to $\mathrm{T}$ in the 609 codon of NQO1 results in no detectable NQO1 activity [16] which may affect rate of $\mathrm{Cr}(\mathrm{VI})$ reduction. Following reduction of $\mathrm{Cr}(\mathrm{VI})$, the associated processes include generation of reactive oxygen species (ROS) leading to oxidative stress and DNA damage [17]. Prior studies have reported formation of 8-hydroxydeoxyguanosine (8-OHdG) base changes, an oxidation product due to occupational exposure of $\mathrm{Cr}(\mathrm{VI})[18,19]$. So, it is of interest to look for role of variation in 8-oxoguanine glycosylase gene ( $h O G G 1$ ) involved in the repair of $8-\mathrm{OHdG}$ base changes [20]. A C to $\mathrm{G}$ nucleotide transversion at position 1,245 in exon 7 of the hOGG1 gene is associated with the substitution of cysteine (Cys) for serine (Ser) at codon 326 which affects the biological activity of hOGG1 protein [21]. Further, glutathione S-transferases (GST), xenobiotic-metabolising enzymes are involved in the metabolic detoxification of various environmental carcinogens, oxidized lipid and DNA products generated by ROS-induced damage to intracellular molecules [22]. Two of the most relevant GST isoenzymes, GSTM1 (mu) and GSTT1 (theta), are nonfunctional (due to deletion of a portion of gene) in appreciable percentage of human population. These deficiencies have been suggested to play an important role in cancer susceptibility [23-25]. Role of GSTT1 and GSTM1 polymorphism in relation to exposure towards other environmental toxicants has previously been demonstrated by our group [26, 27].

We understand that by affecting the individual's ability, genetic polymorphisms of NQO1, hOGG1, GSTM1, and GSTT1 may influence occurrence of dermatological outcomes among general population exposed to $\mathrm{Cr}(\mathrm{VI})$. We conducted the present study which involved residents from $\mathrm{Cr}$ (VI) contaminated areas of Kanpur (Uttar Pradesh, India) [5]. An earlier health impact assessment-based study conducted by us revealed significantly higher prevalence of self-reports for dermal adversities among the residents from the contaminated areas as compared to residents with similar

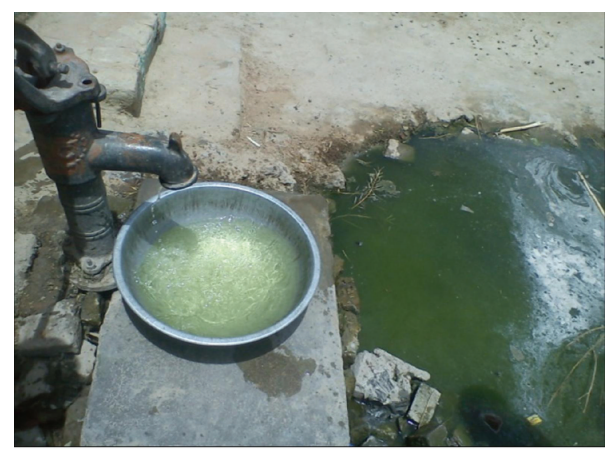

FIGURE 1: Photograph of yellow-colored contaminated water from a handpump.

social and demographic features living in communities without elevated $\mathrm{Cr}(\mathrm{VI})$ levels. We hypothesize that the present study may explain the reason for differences in susceptibility towards $\mathrm{Cr}(\mathrm{VI})$ exposure among the residents.

\section{Materials and Methods}

2.1. Selection of Area. Kanpur, a city in Uttar Pradesh province of India, lies in Indo-Gangetic plain $\left(26.4670^{\circ}\right.$ North and $80.3500^{\circ}$ East). Reportedly, there are large numbers of leather tanneries and chrome sulphate manufacturing units located in and around Kanpur. Wastes from these industries are improperly disposed which has resulted in groundwater contamination at various areas of Kanpur [5]. Levels of $\mathrm{Cr}(\mathrm{VI})$ in groundwater have reached upto 124-258 times higher than the WHO permissible limit in some areas [5, 28, 29].

We selected contaminated communities on the basis of previous reports by Central Pollution Control Board, UP. An area in the vicinity with no history of $\mathrm{Cr}(\mathrm{VI})$ contamination was also selected for a control population. To avoid any exposure misclassification, a standard diphenylcarbazide reagent method was used to estimate $\mathrm{Cr}(\mathrm{VI})$ in groundwater samples [30]. The estimated levels of $\mathrm{Cr}(\mathrm{VI})$ in groundwater from the contaminated area ranged from $8.0-38.4 \mathrm{ppm}$. The mean $\mathrm{Cr}(\mathrm{VI})$ concentration was $19.5 \pm 9.4 \mathrm{ppm}$ which was many folds above WHO permissible limit of $0.05 \mathrm{ppm}$. Figure 1 shows photograph of contaminated yellow water from a handpump.

2.2. Selection of the Study Population. Subjects were recruited through the health camps. Ethical approval for the study was obtained from Institutional Human Ethics Committee of IITR. Before inclusion, written informed consent was obtained from all participants. Inclusion criteria of subjects was age equal to or more than 18 years, duration of residence not less than 5 years, no consumption of bottled water, and no present or past occupational exposure to $\mathrm{Cr}(\mathrm{VI})$. Occupational exposure to $\mathrm{Cr}(\mathrm{VI})$ includes various types of jobs which involve use or manufacture of $\mathrm{Cr}$ compounds for example, leather tanneries, cement, chrome sulphate manufacturing, paint and dye synthesis, chrome plating. 
Nonoccupational exposure to subjects is via environment for example, air, water, food chain. In our study, the exposure to subjects was predominantly through contaminated water.

2.3. Health Examination and Record. A pretested questionnaire was used to gather demographic information. Heath information related with occurrence of dermatological symptoms, namely, itching or reddening of skin, flaky or scaly skin, and their specific histories were recorded in the questionnaire. A medical scientist also examined the subjects in accordance with recommendations outlined in the Declaration of Helsinki [31].

2.4. Blood Sample Collection. Blood samples $(2-3 \mathrm{~mL})$ were collected by venipuncture in EDTA-coated vacutainers (BD Biosciences), were stored at $4^{\circ} \mathrm{C}$, and transported to the laboratory within 3-4 hours.

2.5. Isolation of Genomic DNA. DNA was isolated from whole blood using commercial DNA isolation kit (Qiagen). Dissolved DNA was quantitated by optical density (OD) at $260 \mathrm{~nm}$ using Picodrop Spectrophotometer. DNA samples were stored at $-80^{\circ} \mathrm{C}$ in small aliquots.

2.6. Genotyping for GSTT1, GSTM1 Deletion Polymorphism. Analysis for GSTT1 and GSTM1 genetic polymorphism was done by multiplex PCR [32]. DNA (50 ng) was amplified in a $20 \mu \mathrm{L}$ reaction having 10 pmoles each of primers for GSTT1: $5^{\prime}$ - TT TC TTA CT GGTCCTCACATCTC-3' and $5^{\prime}$-TCACGGGATCATGGCCAGCA-3' and GSTM1: $5^{\prime}$-G A A C T C C C T G A A A A G C T A A A G C- $3^{\prime}$ and $5^{\prime}$ GTTGGGCTCAAATATACGGTGG-3'. As an internal control, exon 7 of the CYPlAl gene was coamplified using the primers: $5^{\prime}$-GAACTGCCACTTCAGCTGTCT- $3^{\prime}$ and $5^{\prime}$ CAGCTGCATTTGGAAGTGCTC-3'. The PCR conditions consisted of an initial melting temperature of $94^{\circ} \mathrm{C}(5 \mathrm{~min})$ followed by 35 cycles of melting $\left(94^{\circ} \mathrm{C}, 2 \mathrm{~min}\right)$, annealing $\left(59^{\circ} \mathrm{C} 1 \mathrm{~min}\right)$, and extension $\left(72^{\circ} \mathrm{C} 1 \mathrm{~min}\right)$. A final extension step $\left(72^{\circ} \mathrm{C}\right)$ of $10 \mathrm{~min}$ terminates the process. The PCR products from coamplification of GSTT1, GSTM1, and CYPlA1 genes were then analyzed electrophoretically on $2 \%$ agarose gel. GSTT1 and GSTM1 wild genotypes yield band of 480 basepair (bp) and 215 bp, respectively, while no band is seen in case of deletion. CYPlAl gave band of size $315 \mathrm{bp}$ in all the samples.

2.7. Genotyping for NQO1 (C609T) Polymorphism. Detection of C609T transition at gene NQO1 was done using method reported by Harth et al. [33]. DNA (100 ng) was amplified using 10 pmoles of primers: $5^{\prime}$-GAGACGCTAGCTCTGAACTGATT- ${ }^{\prime}$ and $5^{\prime}$-AGCAAAATACAGATGGTGTCTCAT- $3^{\prime}$. Thermal cycling conditions were firstly, $4 \mathrm{~min}$ at $94^{\circ} \mathrm{C}, 30$ cycles of $1 \mathrm{~min}$ at $94^{\circ} \mathrm{C}, 1 \mathrm{~min}$ at $62^{\circ} \mathrm{C}, 1 \mathrm{~min}$ at $72^{\circ} \mathrm{C}$ and lastly $7 \mathrm{~min}$ at $72^{\circ} \mathrm{C}$. PCR product $(10 \mu \mathrm{L})$ of $300 \mathrm{bp}$ was digested with HinfI restriction enzyme(Fermentas) and run on $2.5 \%$ agarose gel. Wild genotype $(\mathrm{C} / \mathrm{C})$ showed one $280 \mathrm{bp}$ band, heterozygous $(\mathrm{C} / \mathrm{T})$ showed 3 bands of $280 \mathrm{bp}, 164 \mathrm{bp}$, and $116 \mathrm{bp}$ and mutant genotype (T/T) showed 2 bands of $164 \mathrm{bp}$ and $116 \mathrm{bp}$.

2.8. Genotyping for hOGG1 (C1245G) Polymorphism. The C1245G transition at hOGG1 gene was detected using method reported by Wang et al. [34]. DNA was amplified using primers: $5^{\prime}$-AGGGGAAGGTGCTTGGGGAA-3' and $5^{\prime}$-ACTGTCACTAGTCTCACCAG-3'. PCR consisted of an initial denaturation step for $5 \mathrm{~min}$ at $94^{\circ} \mathrm{C}, 35$ cycles of denaturation for $20 \mathrm{~s}$ at $94^{\circ} \mathrm{C}$, primer annealing for $20 \mathrm{~s}$ at $60^{\circ} \mathrm{C}$, and primer extension for $40 \mathrm{~s}$ at $72^{\circ} \mathrm{C}$, followed by a final extension step for $7 \mathrm{~min}$ at $72^{\circ} \mathrm{C}$. PCR product $(10 \mu \mathrm{L})$ of size 200 bp was digested using Fnu4HI restriction enzyme (Fermentas) and run on 2.5\% agarose gel. Heterozygous subjects (CG) exhibited two fragments (200 and $100 \mathrm{bp}$ ) while homozygous wild type $(\mathrm{C} / \mathrm{C})$ and mutant $(\mathrm{GG})$ genotype exhibited single fragment of $200 \mathrm{bp}$ and $100 \mathrm{bp}$, respectively.

2.9. Sequencing. The gene products for GSTT1, GSTM1, NQO1 and hOGG1 were sequenced. The amount of PCR product used in sequencing for NQO1, and $h O G G 1$ was $5 \mathrm{ng}$, while it was $7 \mathrm{ng}$ for GSTM1 and $12 \mathrm{ng}$ for GSTT1 [35].

2.10. Statistical Analysis. Descriptive statistics for exposed and control group were presented as mean and standard deviation. Frequencies and percentages were shown for categorical variables. Student's $t$-test and chi-square test were used to find out difference in distribution for sociodemographic variables among the two groups. Among exposed group, subjects afflicted with dermatological symptoms were regarded as "symptomatic" and the rest were designated as "asymptomatic". Models were generated to analyze comparison among: (1) symptomatic exposed and asymptomatic control subjects; (2) symptomatic exposed and asymptomatic exposed subjects. Logistic regression procedures were used to estimate odds ratios (OR) with 95\% confidence intervals (CI) to see influence of various genotypes on dermatological outcomes. Statistical significance was tested by chi-square test. Main predictor variables considered were genetic variants of the GSTT1, GSTM1, NQO1, and $h O G G 1$ gene. Occurrence of the dermatological adversity (yes/no) was considered as outcome variable. The covariates analyzed were gender, age ( $\leq 35$ and $>35$ years), smoking habit (never versus current or past), and duration of residence ( $\leq 20$ and $>20$ years). Further, multivariate logistic regression analysis was also performed to adjust for confounding effect by the covariates. All the analyses were carried out using SPSS 13 (SPSS, Chicago, USA). A 0.05 cutoff point was set for the $P$ value and applied in all the statistical analyses.

\section{Results}

3.1. Study Population and Its Characteristics. Study population comprised of a total of 146 exposed subjects (mean age \pm SD: $36.29 \pm 14.82$ years) and 148 asymptomatic controls (mean age \pm SD: $39.63 \pm 14.39$ years). Among exposed 


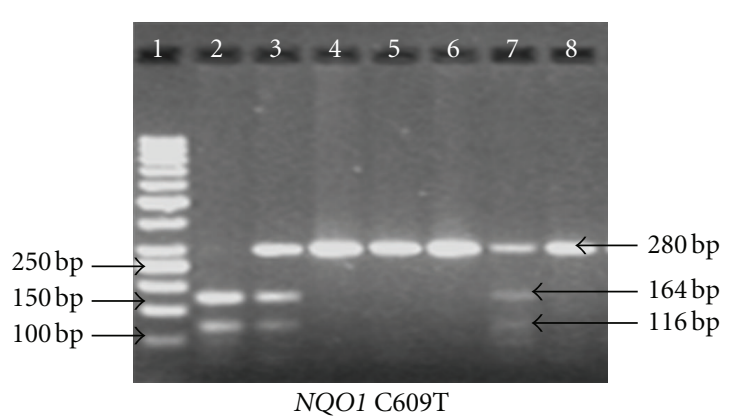

(a)

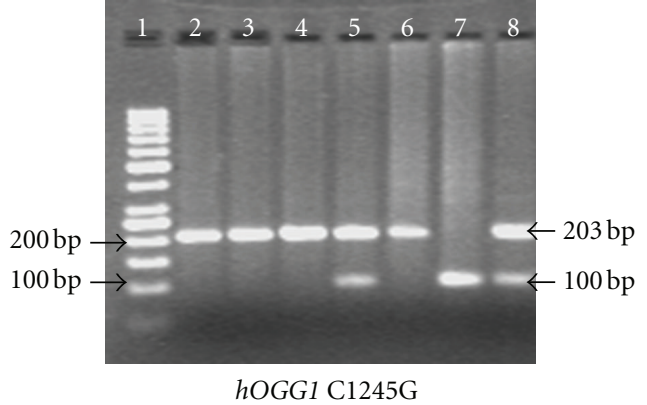

(b)

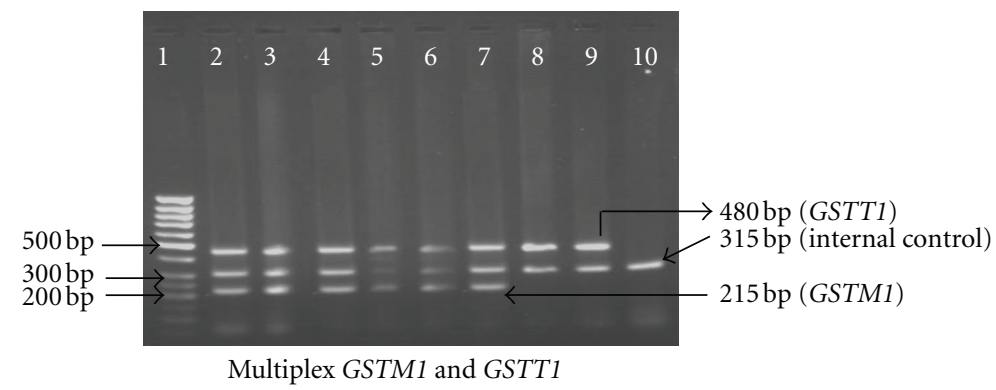

(c)

FIGURE 2: Representative gels of NQO1 C609T, hOGG1 C1245G and multiplex GSTM1 and GSTT1 genotyping.

group, 26\% ( $n=38)$ subjects were having dermal problems, namely, itching, reddening, and crusting of skin. Duration of residence for the exposed subjects at the contaminated areas ranged from 2-79 years (mean \pm SD: $24.17 \pm 15.23$ years). The sociodemographic characteristics of both the groups are shown in Table 1. Exposed population included 79 males and 67 females while control group consisted of 65 males and 83 females. Further, $8.8 \%$ subjects among control group and $19.2 \%$ among exposed group were smokers. There were differences in the number of smokers among two groups. So, we adjusted the risk estimates for any confounding effect by this variable.

3.2. Genotypic Distribution. Figure 2 shows the representative gel of NQO1 C609T, hOGG1 C1245G and multiplex GSTM1 and GSTT1 genotyping. Sequences of PCR products blasted with the reference gene from the database on National Centre for Biotechnology Information (NCBI) gave homology in the range of 96-99\% (Table 2).

The genotypic distribution for GSTT1 and GSTM1, NQO1 and hOGG1 genesamong exposed and control group is shown in Table 3. Frequencies for GSTT1 null and GSTM1 null were $23.3 \%$, and $24 \%$ among exposed population and $14.2 \%$, and $37.8 \%$ among controls. Among exposed group, $38.3 \%, 51.1 \%$, and $10.6 \%$ subjects were wild, heterozygous and mutant genotyped, respectively for NQO1 C609T polymorphism and the respective frequencies among controls were $48.6 \%, 37.2 \%$, and $14.2 \%$. For hOGG1 gene, respective frequencies for wild, heterozygous and mutant genotype were $47.3 \%, 41.1 \%$, and $11.6 \%$ among exposed subjects and $36.5 \%, 53.4 \%$, and $10.1 \%$ among controls. Hardy Weinberg equilibrium test showed accordance for
NQO1 and hOGG1 gene in both population groups. The Hardy Weinberg equilibrium could not be tested for GSTT1 and GSTM1 because of the inability of the present PCR protocol to separate heterozygous carriers of the deletion polymorphisms.

3.3. Association between Genetic Polymorphism and Occurrence of Dermal Problems. We compared the distribution for various covariates and genetic polymorphic status of GSTT1 and GSTM1, NQO1 and hOGG1 genes among symptomatic exposed $(n=38)$ and asymptomatic control group $(n=$ 148). It showed no significant difference in distribution among males versus females and subjects with age $\leq 35$ versus age $>35$ years (Table 4 ). However, smoking was found to act as a confounding factor. Exposed group consisted of greater number of smokers (21\%) as compared to controls $(8.8 \%)$ and exposed smokers had higher prevalence of dermal problems as compared to control nonsmokers $(\mathrm{OR}=2.77$; $95 \% \mathrm{CI}=1.055-7.272)$. The difference in the distribution of genetic polymorphic status for GSTT1 gene was found significant with respect to occurrence of dermal complaints. As compared to asymptomatic control group where $14.2 \%$ subjects were null genotyped, symptomatic exposed group was having $29 \%$ subjects having GSTT1 null genotype. Odds ratio showing prevalence of dermal problems among GSTT1 null genotyped as compared to wild genotyped subjects was 2.46 (95\% CI $=1.064-5.705)$. However, after adjustment for smoking, influence of GSTT1 polymorphism did not remain significant, although the odds ratio $(\mathrm{OR}=2.53)$ did not change much. Further, there were no significant differences in distribution for NQO1 $(\mathrm{OR}=1.18)$, hOGG1 $(\mathrm{OR}=0.905)$ and GSTM1 $(\mathrm{OR}=0.96)$ gene among these groups. 
TABle 1: Demographic characteristics of the study participants.

\begin{tabular}{|c|c|c|c|c|}
\hline Characteristics & Category & $\begin{array}{l}\text { Exposed group } \\
\quad(N=146)\end{array}$ & $\begin{array}{l}\text { Control group } \\
(N=148)\end{array}$ & $P$ value \\
\hline Mean age & Mean \pm SD & $36.29 \pm 14.82$ & $39.63 \pm 14.39$ & $0.086^{\mathrm{a}}$ \\
\hline \multirow{2}{*}{ Number of subjects } & Males & $79(54)$ & $65(44)$ & \multirow{2}{*}{$0.0805^{\mathrm{b}}$} \\
\hline & Females & $67(46)$ & $83(56)$ & \\
\hline Smoking status & Smokers & $28(19.2)$ & $13(8.8)$ & $0.0101^{\mathrm{b}}$ \\
\hline Symptom category & Symptomatic & $38(26)$ & 一 & \\
\hline
\end{tabular}

SD: standard deviation.

Number in parenthesis denotes percentage.

a $P$ value for continuous variables calculated using Student's $t$-test.

${ }^{\mathrm{b}} P$ value for categorical variables calculated using Chi-square test.

TABLE 2: Summary of accession number of individual genes and their products sequenced after purification with percentage homology.

\begin{tabular}{|c|c|c|c|c|}
\hline Gene & Accession number & Product & Product RFLP & Homology (\%) \\
\hline GSTT1 & NM_000853 & $480 \mathrm{bp}$ & - & 96.6 \\
\hline GSTM1 & NM_000561 & $215 \mathrm{bp}$ & - & 97.3 \\
\hline NQO1 C609T & NM_000903 & 300 & $280,164,116$ & 99 \\
\hline hOGG1 C1245G & NM_016819.3 & 200 & $100 \mathrm{bp}$ & 99 \\
\hline
\end{tabular}

Table 5 depicts distribution of covariates and genetic polymorphic status among symptomatic exposed $(n=38)$ and asymptomatic exposed group $(n=108)$. It was observed that the occurrence of dermal problems among exposed group was independent of gender, agecategory ( $\leq 35$ versus $>35$ years), smoking status (never versus current or past), and duration of the residence ( $\leq 20$ years versus $>20$ years). Analysis with genetic polymorphic status showed significant difference in distribution for GSTM1 genotypes. Exposed symptomatic group consisted of $36.8 \%$ subjects who were GSTM1 null genotyped as compared to asymptomatic where only $19.4 \%$ subjects were null. Odds ratio showed higher prevalence of dermal problems in null genotyped subjects compared to wild genotyped subjects $(\mathrm{OR}=2.42$; $95 \% \mathrm{CI}=1.071-5.451)$. The association with other genes, although, did not reach statistically significant level, however, higher odds ratios (OR > 20) were found in case of both hOGG1 mutant ( $\mathrm{OR}=2.07 ; 95 \% \mathrm{CI}=0.96-4.469)$ and GSTT1 null genotype $(\mathrm{OR}=1.51 ; 95 \% \mathrm{CI}=0.651-$ 3.484) compared to their respective wild genotypes. On the contrary, NQO1 genetic polymorphism showed reverse association and subjects with null genotype had lower prevalence for dermal problems as compared to those having wild genotype $(\mathrm{OR}=0.71 ; 95 \% \mathrm{CI}=0.329-1.529)$.

\section{Discussion}

In our previous studies on the population residing in $\mathrm{Cr}(\mathrm{VI})$ contaminated areas, higher prevalence of self-reports for dermal complaints, namely, itching, reddening, and scaling of skin was observed with higher mean Cr levels (approximately 6 folds) in hair of these residents compared to controls having similar sociodemographic status (unpublished observations). However, we noticed that not all residents were at risk to the dermal outcomes. Therefore, an attempt has been made to find out genetic linkages, if any, in causing wide variability in the outcomes among $\mathrm{Cr}(\mathrm{VI})$ exposed individuals. The general population living in hexavalent chromium-contaminated areas of Kanpur provided us with the opportunity to explore the role of genetic variants in causing variable response towards dermal problems among exposed individuals and also in comparison with unexposed individuals.

In the present study on genetic variability, we found significant modification in the risk by GSTM1 genetic polymorphism. It was observed that absence of GSTM1 gene activity among residents from $\mathrm{Cr}(\mathrm{VI})$ contaminated areas was acting as a predisposing factor towards occurrence of dermal problems. This is suggestive of the role of GSTM1 gene in the pathogenesis of dermal problems among subjects exposed to $\mathrm{Cr}(\mathrm{VI})$.

Literature reports that a number of skin diseases are associated with oxidative stress [36] with a very specific role of GSTM1 in protection against oxidative stress [37]. GSTM1 catalyzes the conjugation of DNA hydroperoxides, namely, 4-hydroxynonenal, linoleic acid hydroperoxide which are mutagenic and cytotoxic product of lipid peroxidation [37]. Further, 5-hydroxymethyluracil, a mutagenic compound that is formed by either oxidative attack on the methyl group of the thymine base of DNA or from deamination of products formed by oxidation of 5-methylcytosine was also taken care by GSTM1 [38]. Skin allergies are more common among individuals with genetic absence of GSTM1 [39]. Arsenic-induced skin lesions [40] and non-melanoma carcinoma risk [41] are also reported in association with GSTM1 null genotype. $\mathrm{Cr}(\mathrm{VI})$ induces carcinogenesis via oxidative stress pathway [42]. The role of glutathione (GSH) in $\mathrm{Cr}(\mathrm{VI})$ reduction inside the cell has also been highlighted [43]. Increased frequency of sister chromatid exchange (SCE) 
TABLE 3: Genotypic distribution for GSTT1, GSTM1, NQO1 C609T, and hOGG1 C1245G genes among exposed and control group.

\begin{tabular}{|c|c|c|c|}
\hline Characters & Category & $\begin{array}{l}\text { Exposed group } \\
(N=146) n(\%)\end{array}$ & $\begin{array}{c}\text { Control group } \\
(N=148) n(\%)\end{array}$ \\
\hline \multirow{2}{*}{ GSTT1 } & Wild & $112(76.7)$ & $127(85.8)$ \\
\hline & Null & $34(23.3)$ & $21(14.2)$ \\
\hline \multirow{2}{*}{ GSTM1 } & Wild & $111(76)$ & $92(62.2)$ \\
\hline & Null & $35(24)$ & $56(37.8)$ \\
\hline \multirow{3}{*}{ NQO1 } & Wild (C/C) & $54(38.3)$ & $72(48.6)$ \\
\hline & Heterozygous $(\mathrm{C} / \mathrm{T})$ & $72(51.1)$ & $55(37.2)$ \\
\hline & Mutant (T/T) & $15(10.6)$ & $21(14.2)$ \\
\hline \multirow{3}{*}{ hOGG1 } & Wild (C/C) & $69(47.3)$ & $54(36.5)$ \\
\hline & Heterozygous (C/G) & $60(41.1)$ & $79(53.4)$ \\
\hline & Mutant (G/G) & $17(11.6)$ & $15(10.1)$ \\
\hline
\end{tabular}

Data for some samples are missing due to limited sample volume.

TABLE 4: Influence of various covariates and genotypes on dermatological adversities among exposed group compared with asymptomatic control group.

\begin{tabular}{|c|c|c|c|c|}
\hline Characters & Category & $\begin{array}{l}\text { Exposed SYMP } \\
(N=38) n(\%)\end{array}$ & $\begin{array}{l}\text { Control ASYMP } \\
(N=148) n(\%)\end{array}$ & OR $(95 \% \mathrm{CI})$ \\
\hline \multirow{2}{*}{ Sex } & Males & $20(52.6)$ & $65(43.9)$ & 1 \\
\hline & Females & $18(47.4)$ & $83(56.1)$ & $0.71(0.345-1.441)$ \\
\hline \multirow{2}{*}{ Age (years) } & $\leq 35$ & $20(52.6)$ & $69(46.6)$ & 1 \\
\hline & $>35$ & $18(47.4)$ & $79(53.4)$ & $0.67(0.408-1.109)$ \\
\hline \multirow{2}{*}{ Smoking } & Never & $30(79)$ & $135(91.2)$ & 1 \\
\hline & Current/past & $8(21)$ & $13(8.8)$ & $2.77(1.055-7.272)^{*}$ \\
\hline \multirow{3}{*}{ GSTT1 } & Wild & $27(71)$ & $127(85.8)$ & 1 \\
\hline & Null & $11(29)$ & $21(14.2)$ & $2.46(1.064-5.705)^{*}$ \\
\hline & & & & $2.53(0.946-6.77)^{\#}$ \\
\hline \multirow{2}{*}{ GSTM1 } & Wild & $24(63.2)$ & $92(62.2)$ & 1 \\
\hline & Null & $14(36.8)$ & $56(37.8)$ & $0.96(0.458-2.005)$ \\
\hline \multirow{2}{*}{ NQO1 } & Wild $(\mathrm{C} / \mathrm{C})$ & $16(44.4)$ & $72(48.65)$ & 1 \\
\hline & Mutant $(\mathrm{C} / \mathrm{T}+\mathrm{T} / \mathrm{T})$ & $20(55.6)$ & $76(51.35)$ & $1.18(0.569-2.463)$ \\
\hline \multirow{2}{*}{ hOGG1 } & Wild $(\mathrm{C} / \mathrm{C})$ & $13(34.2)$ & $54(36.5)$ & 1 \\
\hline & Mutant $(\mathrm{C} / \mathrm{G}+\mathrm{G} / \mathrm{G})$ & $25(65.8)$ & $94(63.5)$ & $0.905(0.428-1.915)$ \\
\hline
\end{tabular}

SYMP: symptomatic, ASYMP: asymptomatic, OR: odds ratio, CI: confidence interval; ${ }^{\#}$ odds ratio adjusted for smoking; ${ }^{*} P<0.05$.

among Cr workers with GSTM1 null genotype as opposed to nonnull genotype individuals is observed [44].

There are different distribution patterns of GSTM1 null genotype among different ethnic groups which ranges from $23 \%$ to $48 \%$ in African populations, 33\% to $63 \%$ in Asian populations, $39 \%$ to $62 \%$ in European populations, and $23 \%$ to $62 \%$ in U.S. populations [45]. Further, interindividual as well as interethnic variations alongwith toxicants exposure to the population across the world might be showing interindividual variations in the toxicant effect relationship.

The genetic associations with other genes involved in $\mathrm{Cr}$ metabolism and disposition were not significant; however, this indicates possible influence of such genetic polymorphisms on the exposed population. Formation of 8-hydroxy deoxyguanosine has been demonstrated on occupationally exposed workers $[18,19]$. In another study involving school children from communities near thermal power plant, greater urinary 8-OHdG concentration was found among children having elevated urinary chromium levels than those with lower urinary chromium [46]. Association of GSTT1 genetic polymorphism with dermal manifestations [47] and its influence in causing variability among chrome plating workers is also described [48]. The role of NQO1 in cellular mechanism of $\mathrm{Cr}(\mathrm{VI})$ reduction has also been introduced [15]. Advocating the role of NQO1 in $\mathrm{Cr}(\mathrm{VI})$ reduction raises possibility of increased production of lower oxidation state of chromium which is more toxic and concomitant production of ROS [14]. So, the compromised activity of NQO1 due to genetic polymorphism may give protection from damage caused by $\mathrm{Cr}$ (III) production inside the cell. This might be the cause behind higher prevalence of dermal outcomes among NQO1 wild genotyped subjects.

Further, elicitation of health outcomes among human population depends not only on exposure conditions on 
TABLE 5: Influence of various covariates and genotypes on dermatological adversities among symptomatic exposed compared with asymptomatic exposed group.

\begin{tabular}{|c|c|c|c|c|}
\hline Characters & Category & $\begin{array}{l}\text { Exposed SYMP } \\
(N=38) n(\%)\end{array}$ & $\begin{array}{l}\text { Exposed ASYMP } \\
(N=108) n(\%)\end{array}$ & OR $(95 \% \mathrm{CI})$ \\
\hline \multirow{2}{*}{ Sex } & Males & $20(52.6)$ & $59(54.6)$ & 1 \\
\hline & Females & $18(47.4)$ & $49(45.4)$ & $1.08(0.517-2.273)$ \\
\hline \multirow{2}{*}{ Age (years) } & $\leq 35$ & $20(52.6)$ & $61(56.5)$ & 1 \\
\hline & $>35$ & $18(47.4)$ & $47(43.5)$ & $1.17(0.556-2.453$ \\
\hline \multirow{2}{*}{ Smoking } & Never & $30(79)$ & $88(81.5)$ & 1 \\
\hline & Current/past & $8(21)$ & $20(18.5)$ & $1.17(0.468-2.94)$ \\
\hline \multirow{2}{*}{$\begin{array}{l}\text { Duration of } \\
\text { residence (years) }\end{array}$} & $\leq 20$ & $19(50)$ & $62(57.4)$ & 1 \\
\hline & $>20$ & $19(50)$ & $46(42.6)$ & $1.35(0.642-2.83)$ \\
\hline \multirow{2}{*}{ GSTT1 } & Wild & $27(71)$ & $85(78.7)$ & 1 \\
\hline & Null & $11(29)$ & $23(21.3)$ & $1.51(0.651-3.484)$ \\
\hline \multirow{2}{*}{ GSTM1 } & Wild & $24(63.2)$ & $87(80.6)$ & 1 \\
\hline & Null & $14(36.8)$ & $21(19.4)$ & $2.42(1.071-5.451)^{*}$ \\
\hline \multirow{2}{*}{ NQO1 } & Wild (C/C) & $16(44.4)$ & $38(36.2)$ & 1 \\
\hline & Mutant $(\mathrm{C} / \mathrm{T}+\mathrm{T} / \mathrm{T})$ & $20(55.6)$ & $67(63.8)$ & $0.71(0.329-1.529)$ \\
\hline \multirow{2}{*}{ hOGG1 } & Wild (C/C) & $13(34.2)$ & $56(51.8)$ & 1 \\
\hline & Mutant $(\mathrm{C} / \mathrm{G}+\mathrm{G} / \mathrm{G})$ & $25(65.8)$ & $52(48.2)$ & $2.07(0.96-4.469)$ \\
\hline
\end{tabular}

SYMP: symptomatic, ASYMP: asymptomatic, OR: odds ratio, CI: confidence interval; ${ }^{*} P<0.05$.

which humans have no control, but also, on factors such as smoking for which a personal choice exists. Smoking is strongly associated with numerous dermatologic conditions including squamous cell carcinoma and psoriasis, although, the evidence linking smoking and melanoma, eczema, and acne is inconclusive [49]. Synergistic effect between arsenic exposure and tobacco smoking on risk of skin lesions was reported by Chen et al. [50]. We also observed significant influence of smoking on the dermal outcomes, in association with environmental exposure to $\mathrm{Cr}(\mathrm{VI})$. Thus, we understand that smoking status of subject should be taken into consideration while determining health risk due to a toxic environmental agent.

We accept that genetic research is not applicable for direct public health purposes, as it currently stands. Moreover, the ethical issues on revealing personal genetic information are also considerable. However, such studies can be worthwhile for the investigation of disease mechanisms, to give insights on potential therapies or to discover unidentified etiological agents involved in the case of diseases whose etiology is still unknown. These genetic studies are of high relevance for populations being chronically exposed to a toxic agent under low concentrations, a usually common scenario within residential settings.

\section{Conclusion}

The present study reports that GSTM1 genetic polymorphism may cause individuals bearing high-risk genotype more susceptible towards $\mathrm{Cr}(\mathrm{VI})$ exposure associated dermal outcomes. This could well explain why environmental exposures have aggravated effects, if they occur in a population of vulnerable subjects. However, more studies on role of genetic polymorphisms in association with $\mathrm{Cr}(\mathrm{VI})$ exposure among different populations are needed. With the increasing $\mathrm{Cr}(\mathrm{VI})$ toxic burden in vicinity of the human habitat, unraveling the role of such factors involved in modulation of toxic response is highly needed. Knowledge gained, thus, may not only help in screening high-risk groups but, in the long run, may also pave the path for personalized therapeutics measures.

\section{Acknowledgments}

The authors are grateful to Dr. K. C. Gupta, Director, IITR for his support and encouragement throughout the study. The authors also acknowledge Mr. Rakesh Jaiswal (NGO "Ecofriends") for local support at Kanpur. The authors thank Mr. Ramsurat and Ms. Mumtaz Jahan for their technical support during the study. The authors are also thankful to all the study participants for their cooperation in this study. P. sharma acknowledges the fellowship support from University Grant Commission, New Delhi.

\section{References}

[1] G. S. Morris, K. A. Guidry, M. Hegsted, and D. L. Hasten, "Effects of dietary chromium supplementation on cardiac mass, metabolic enzymes, and contractile proteins," Nutrition Research, vol. 15, no. 7, pp. 1045-1052, 1995.

[2] NIOSH, "Comments on the Occupational Safety and Health Administration request for information on occupational exposure to hexavalent chromium (CrVI)," OSHA Docket No. H-0054a. NIOSH policy statements. Cincinnati, Ohio, USA: U.S. Department of Health and Human Services, Public Health Service, Centers for Disease Control and Prevention, National Institute for Occupational Safety and Health, 2002. 
[3] J. Zhang and X. Li, "Chromium pollution of soil and water in Jinzhou," Chinese Journal of Preventive Medicine, vol. 21, no. 5, pp. 262-264, 1987.

[4] T. Burke, J. Fagliano, M. Goldoft, R. E. Hazen, R. Iglewicz, and T. McKee, "Chromite ore processing residue in hudson county, New Jersey," Environmental Health Perspectives, vol. 92, pp. 131-137, 1991.

[5] CPCB, "Report on Groundwater quality in Kanpur, status, sources and control measures. Central Pollution Control Board," no. GWQS/8/1996-97, 1997.

[6] TMBGS, "Survey of Health Effects from Chromium Contamination: Fourth Report," Tokyo Metropolitan Government Bureau of Sanitation Tokyo, Japan, March, 1987.

[7] P. McCarron and T. J. Peters, "Self reported health of people in an area contaminated by chromium waste: interview study," British Medical Journal, vol. 320, no. 7226, pp. 11-15, 2000.

[8] G. E. Corbett, D. G. Dodge, E. O'Flaherty et al., "In vitro reduction kinetics of hexavalent chromium in human blood," Environmental Research, vol. 78, no. 1, pp. 7-11, 1998.

[9] B. D. Kerger, D. J. Paustenbach, G. E. Corbett, and B. L. Finley, "Absorption and elimination of trivalent and hexavalent chromium in humans following ingestion of a bolus dose in drinking water," Toxicology and Applied Pharmacology, vol. 141, no. 1, pp. 145-158, 1996.

[10] B. L. Finley, B. D. Kerger, G. E. Corbett et al., "Human ingestion of chromium (VI) in drinking water: pharmacokinetics following repeated exposure," Toxicology and Applied Pharmacology, vol. 142, no. 1, pp. 151-159, 1997.

[11] Q. Zhang, T. Kluz, K. Salnikow, and M. Costa, "Comparison of the cytotoxicity, cellular uptake, and DNA-protein crosslinks induced by potassium chromate in lymphoblast cell lines derived from three different individuals," Biological Trace Element Research, vol. 86, no. 1, pp. 11-22, 2002.

[12] J. Zelger and H. Wachter, "On the relationships between chromate and dichromate allergy. A contribution to the analysis of chromium (VI) allergy," Dermatologica, vol. 132, no. 1, pp. 45-50, 1966.

[13] M. H. Medina, J. A. Correa, and C. Barata, "Microevolution due to pollution: possible consequences for ecosystem responses to toxic stress," Chemosphere, vol. 67, no. 11, pp. 2105-2114, 2007.

[14] X. Shi, A. Chiu, C. T. Chen, B. Halliwell, V. Castranova, and V. Vallyathan, "Reduction of chromium (VI) and its relationship to carcinogenesis," Journal of Toxicology and Environmental Health B, vol. 2, no. 1, pp. 87-104, 1999.

[15] S. De Flora, A. Morelli, C. Basso, M. Romano, D. Serra, and A. De Flora, "Prominent role of DT-diaphorase as a cellular mechanism reducing chromium (VI) and reverting its mutagenicity," Cancer Research, vol. 45, no. 7, pp. 3188-3196, 1985.

[16] K. T. Kelsey, D. Ross, R. D. Traver et al., "Ethnic variation in the prevalence of a common $\mathrm{NAD}(\mathrm{P}) \mathrm{H}$ quinone oxidoreductase polymorphism and its implications for anti-cancer chemotherapy," British Journal of Cancer, vol. 76, no. 7, pp. 852-854, 1997.

[17] T. J. O'Brien, S. Ceryak, and S. R. Patierno, “Complexities of chromium carcinogenesis: role of cellular response, repair and recovery mechanisms," Mutation Research, vol. 533, no. 1-2, pp. 3-36, 2003.

[18] N. J. Hodges, B. Ádám, A. J. Lee, H. J. Cross, and J. K. Chipman, "Induction of DNA-strand breaks in human peripheral blood lymphocytes and A549 lung cells by sodium dichromate: association with 8-oxo-2-deoxyguanosine formation and inter-individual variability," Mutagenesis, vol. 16, no.
6, pp. 467-474, 2001.

[19] H. W. Kuo, S. F. Chang, K. Y. Wu, and F. Y. Wu, "Chromium (VI) induced oxidative damage to DNA: increase of urinary 8-hydroxydeoxyguanosine concentrations (8-OHdG) among electroplating workers," Occupational and Environmental Medicine, vol. 60, no. 8, pp. 590-594, 2003.

[20] P. Vodicka, R. Kumar, R. Stetina et al., "Genetic polymorphisms in DNA repair genes and possible links with DNA repair rates, chromosomal aberrations and single-strand breaks in DNA," Carcinogenesis, vol. 25, no. 5, pp. 757-763, 2004.

[21] T. Kohno, K. Shinmura, M. Tosaka et al., "Genetic polymorphisms and alternative splicing of the hOGG1 gene, that is involved in the repair of 8-hydroxyguanine in damaged DNA," Oncogene, vol. 16, no. 25, pp. 3219-3225, 1998.

[22] J. D. Hayes and R. C. Strange, "Glutathione S-transferase polymorphisms and their biological consequences," Pharmacology, vol. 61, no. 3, pp. 154-166, 2000.

[23] S. J. Lee, S. H. Cho, S. K. Park et al., "Combined effect of glutathione S-transferase M1 and T1 genotypes on bladder cancer risk," Cancer Letters, vol. 177, no. 2, pp. 173-179, 2002.

[24] Z. Deng, Y. Wei, and Y. Ma, "Glutathione-S-transferase M1 genotype in patients with hepatocellular carcinoma," Zhonghua Zhong Liu Za Zhi, vol. 23, no. 6, pp. 477-479, 2001.

[25] C. H. Sierra-Torres, W. W. Au, C. D. Arrastia et al., "Polymorphisms for chemical metabolizing genes and risk for cervical neoplasia," Environmental and Molecular Mutagenesis, vol. 41, no. 1, pp. 69-76, 2003.

[26] M. Kumar, L. K. S. Chauhan, B. N. Paul, S. K. Agarwal, and S. K. Goel, "GSTM1, GSTT1, and GSTP1 polymorphism in North Indian population and its influence on the hydroquinone-induced in vitro genotoxicity," Toxicology Mechanisms and Methods, vol. 19, no. 1, pp. 59-65, 2009.

[27] M. Kumar, S. Tewari, P. Sharma et al., "Study of genetic polymorphism in solvent exposed population and its correlation to in vitro effect of trichloroethylene on lymphocytes," Journal of Environmental Biology, vol. 30, no. 5, pp. 685-691, 2009.

[28] CGWB, "Groundwater Pollution Studies in Unnao-Kanpur Industrial Areas, Uttar Pradesh," Central Ground Water Board, Lucknow, India, 2000.

[29] I. R. Schaffner, R. K. Singh, S. T. R. Lamb, and D. N. Kirkland, "Enhanced bioremediation pilot study of A Cr(VI)impacted overburden groundwater system in Kanpur, Uttar Pradesh, India," in Proceedings of the 23rd Annual International Conference on Soils Sediments and Water, pp. 1-18, 2010.

[30] APHA, Standard Methods for the Examination of Water and Wastewater, Washington, DC, USA, 21st edition, 2005.

[31] WMA, Ethical Principles for Medical Research Involving Human Subjects, World Medical Association General Assembly, Seoul, Korea, 59th edition, 2008.

[32] S. Z. Abdel-Rahman, R. A. El-Zein, W. A. Anwar, and W. W. $\mathrm{Au}$, "A multiplex PCR procedure for polymorphic analysis of GSTM1 and GSTT1 genes in population studies," Cancer Letters, vol. 107, no. 2, pp. 229-233, 1996.

[33] V. Harth, S. Donat, Y. Ko, J. Abel, H. Vetter, and T. Brüning, "NAD $(\mathrm{P}) \mathrm{H}$ quinone oxidoreductase 1 codon 609 polymorphism and its association to colorectal cancer," Archives of Toxicology, vol. 73, no. 10-11, pp. 528-531, 2000.

[34] C. L. Wang, M. C. Hsieh, S. C. Hsin et al., "The hOGG1 Ser326Cys gene polymorphism is associated with decreased insulin sensitivity in subjects with normal glucose tolerance," Journal of Human Genetics, vol. 51, no. 2, pp. 124-128, 2006.

[35] M. Kumar, S. K. Agarwal, and S. K. Goel, "Lung cancer risk in North Indian population: role of genetic polymorphisms and 
smoking," Molecular and Cellular Biochemistry, vol. 322, no. 1-2, pp. 73-79, 2009.

[36] D. R. Bickers and M. Athar, "Oxidative stress in the pathogenesis of skin disease," Journal of Investigative Dermatology, vol. 126, no. 12, pp. 2565-2575, 2006.

[37] R. Kerb, J. Brockmöller, T. Reum, and I. Roots, "Deficiency of glutathione S-transferases T1 and M1 as heritable factors of increased cutaneous UV sensitivity," Journal of Investigative Dermatology, vol. 108, no. 2, pp. 229-232, 1997.

[38] J. T. Lear, A. G. Smith, R. C. Strange, and A. A. Fryer, "Detoxifying enzyme genotypes and susceptibility to cutaneous malignancy," British Journal of Dermatology, vol. 142, no. 1, pp. 8-15, 2000.

[39] P. C. Tsai, W. Y. Huang, Y. C. Lee, S. H. Chan, and Y. L. Guo, "Genetic polymorphisms in CYP1A1 and GSTM1 predispose humans to PCBs/PCDFs-induced skin lesions," Chemosphere, vol. 63, no. 8, pp. 1410-1418, 2006.

[40] C. V. Breton, M. L. Kile, P. J. Catalano et al., "GSTM1 and APE1 genotypes affect arsenic-induced oxidative stress: a repeated measures study," Environmental Health, vol. 6, article 39, 2007.

[41] A. A. Fryer, H. M. Ramsay, T. J. Lovatt et al., "Polymorphisms in glutathione S-transferases and non-melanoma skin cancer risk in Australian renal transplant recipients," Carcinogenesis, vol. 26, no. 1, pp. 185-191, 2005.

[42] C. M. Thompson, D. M. Proctor, M. Suh et al., "Comparison of the effects of hexavalent chromium in the alimentary canal of $\mathrm{F} 344$ rats and $\mathrm{B} 6 \mathrm{C} 3 \mathrm{~F} 1$ mice following exposure in drinking water: implications for carcinogenic modes of action," The Journal of Toxicological Sciences, vol. 125, no. 1, pp. 79-90, 2011.

[43] S. De Flora and K. E. Wetterhahn, "Mechanisms of chromium metabolism and genotoxicity," Life Chemistry Reports, vol. 7, no. 3, pp. 169-244, 1989.

[44] F. Y. Wu, F. J. Tsai, H. W. Kuo et al., "Cytogenetic study of workers exposed to chromium compounds," Mutation Research, vol. 464, no. 2, pp. 289-296, 2000.

[45] S. C. Cotton, L. Sharp, J. Little, and N. Brockton, "Glutathione S-transferase polymorphisms and colorectal cancer: a huge review," American Journal of Epidemiology, vol. 151, no. 1, pp. 7-32, 2000.

[46] R. H. Wong, C. Y. Kuo, M. L. Hsu et al., "Increased levels of 8-hydroxy-2'-deoxyguanosine attributable to carcinogenic metal exposure among schoolchildren," Environmental Health Perspectives, vol. 113, no. 10, pp. 1386-1390, 2005.

[47] V. A. Vavilin, O. G. Safronova, A. A. Lyapunova et al., "Interaction of GSTM1, GSTT1, and GSTP1 genotypes in determination of predisposition to atopic dermatitis," Bulletin of Experimental Biology and Medicine, vol. 136, no. 4, pp. 388391, 2003.

[48] B. Wang, J. Shiao, C. J. Chen, Y. C. Lee, and Y. L. Guo, “Tumour necrotizing factor- $\alpha$ promoter and GST-T1 genotype predict skin allergy to chromate in cement workers in Taiwan," Contact Dermatitis, vol. 57, no. 5, pp. 309-315, 2007.

[49] A. Freiman, G. Bird, A. I. Metelitsa, B. Barankin, and G. J. Lauzon, "Cutaneous effects of smoking," Journal of Cutaneous Medicine and Surgery, vol. 8, no. 6, pp. 415-423, 2004.

[50] Y. Chen, J. H. Graziano, F. Parvez et al., "Modification of risk of arsenic-induced skin lesions by sunlight exposure, smoking, and occupational exposures in Bangladesh," Epidemiology, vol. 17, no. 4, pp. 459-467, 2006. 

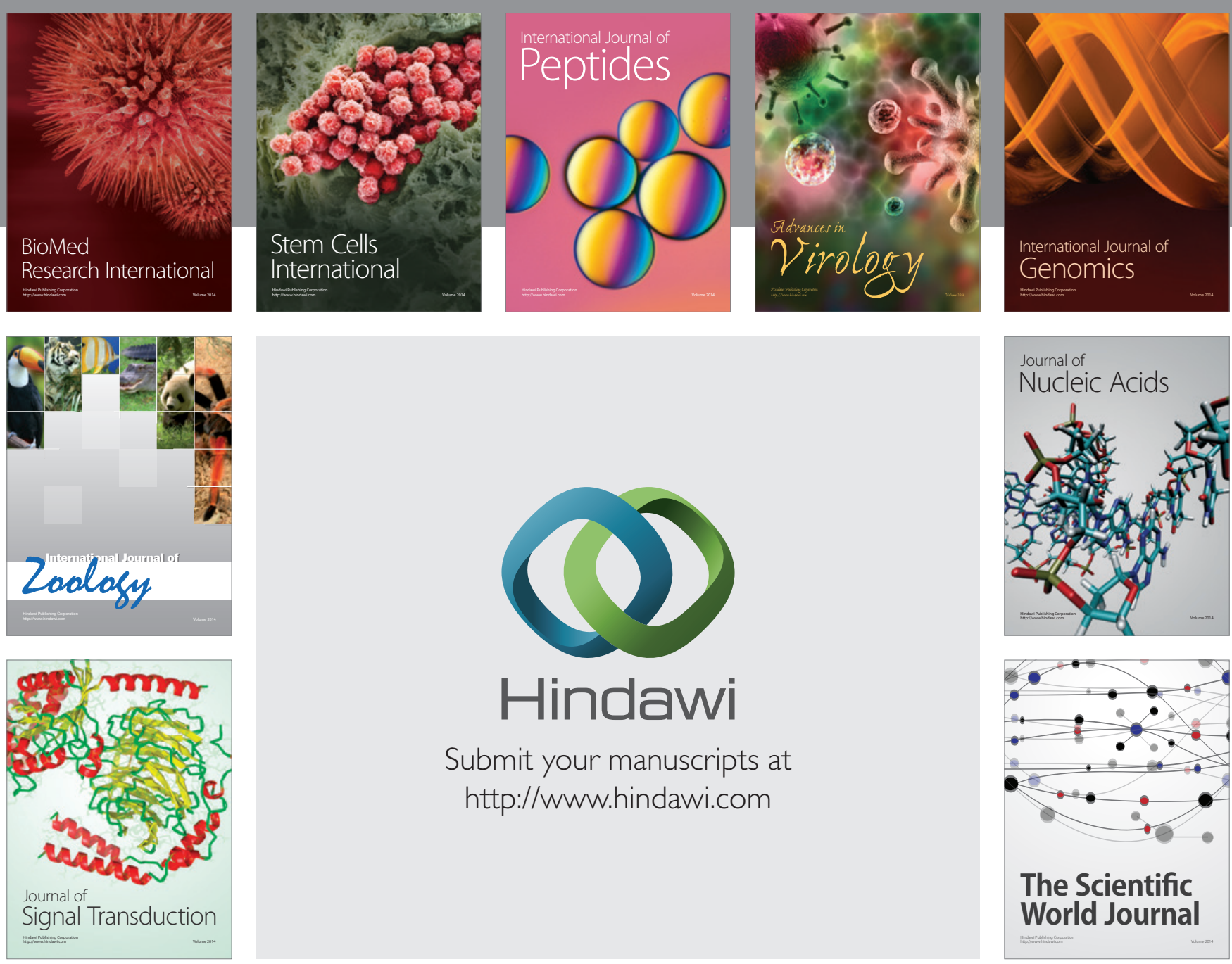

Submit your manuscripts at

http://www.hindawi.com
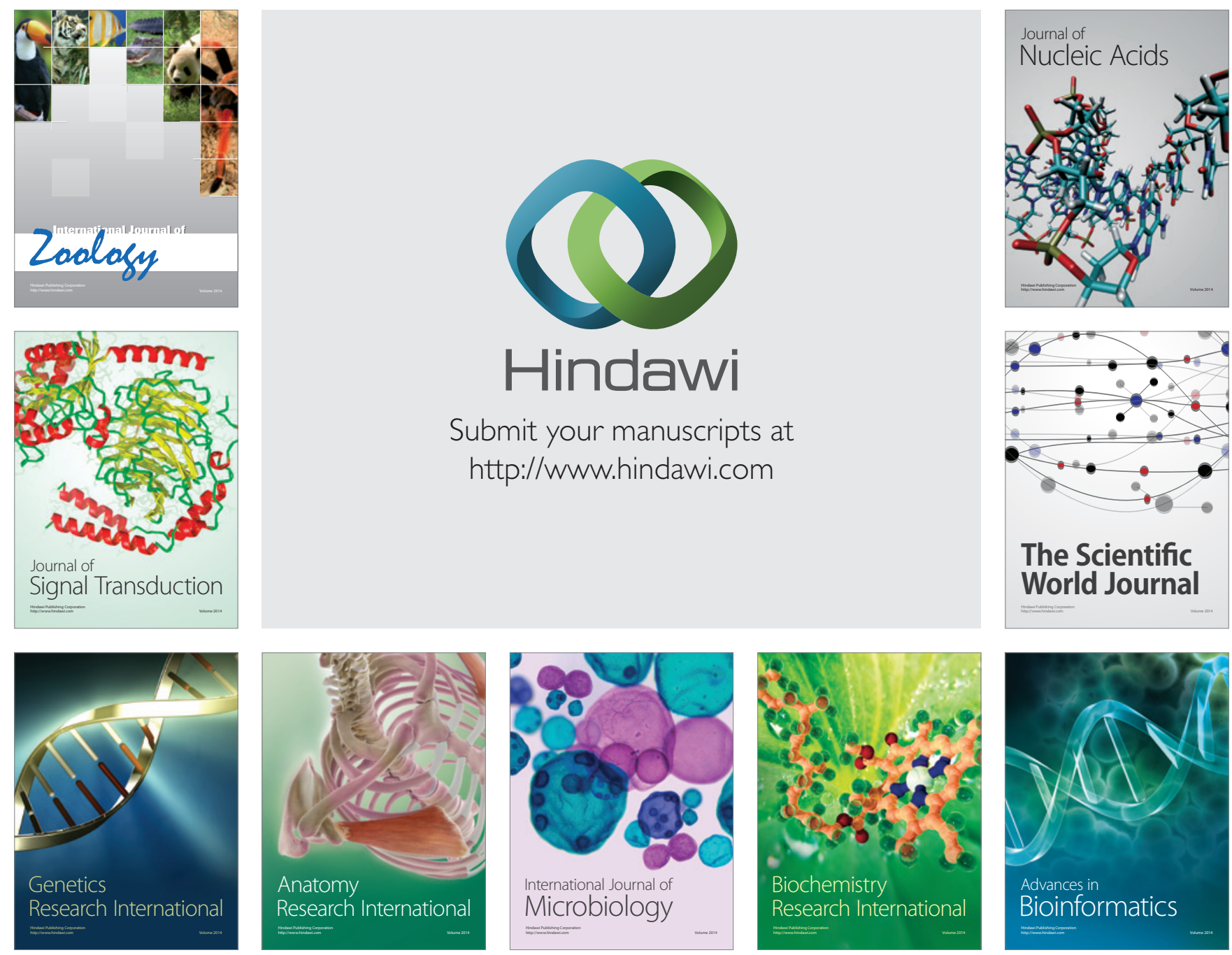

The Scientific World Journal
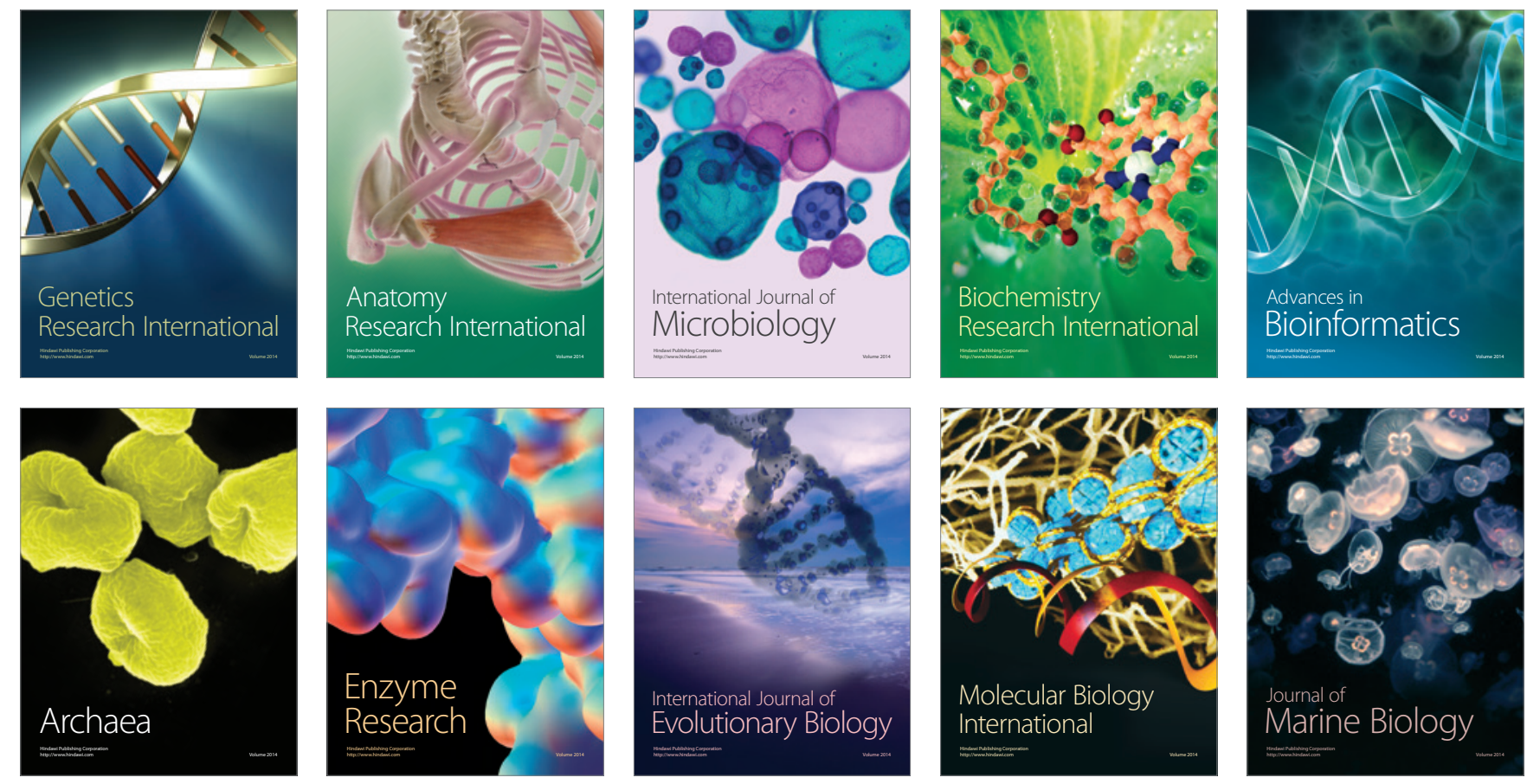